\title{
Relationship between National Culture and Development
}

\author{
Tranos Zuva, Zeleke Worku \\ Vaal University of Technology (VUT) ICT Department, South Africa \\ Tshwane University of Technology (TUT) Business School, South Africa \\ tranosz@vut.ac.za,WorkuZ@tut.ac.za
}

\begin{abstract}
Culture, as it is defined and well understood, differentiates one group from the other; in more general form, one country from the other. Culture then influences the behaviour and how we think in our everyday lives but so far culture of any group can only be measured in terms of a collection of cultural dimensions. This has made it difficult to establish whether there is any relationship between culture and any other social factors. In this study we derived national culture index from the four (4) Hofstede cultural dimensions (power (equality versus inequality), collectivism (versus individualism), uncertainty avoidance (versus uncertainty tolerance), masculinity (versus femininity)) using geo-mean formula. We then investigated whether there is any relationship between national culture index and national development index. In doing this we endeavoured to answer the question "Is There Really a Relationship Between Culture and Development?" posed by Mbakogu (2004:38). The data used for our experiments for Hofstede's dimensions of national culture values were retrieved from Hofstede website that has an open licence for academic researchers. Data for human development national index were retrieved from UNDP website (Letter of consent was obtained from UNDP officials). The Pearson correlation coefficient was calculated $(r=0.083, p=0.502>0.05)$, which indicated that there is very negligible positive relationship between cultural index values and the development index values. Since the value of $p$ is greater than the significance level of 0.05 , we concluded that there is inconclusive evidence about the significance of the association established between National Culture Index and National Development Index. Since we currently have a national culture index, researchers can now talk about culture as a homogeneous unit. Researchers may use the national culture index to investigate relationship between culture and any other social factors. In future we intend to use other cultural dimensions proposed by other researchers to present a national culture index.
\end{abstract}

Keywords: Hofstede cultural dimensions, National development index, National cultural index

\section{Introduction}

National culture and national development are very complex concepts and difficult to define. Many authors gave their view of culture and development thus there are so many definitions in literature (Morden, 2016; Albu, 2006; Aluko, 2003). Researchers endeavoured to measure national culture and national development, giving a vast array of cultural measurements and developmental measurements of nations (Hofstede, 2011; Schwartz, 2008). Through these measurements researchers endeavoured to establish relationships within culture and development (Sempere, 2011; Grosser \& Lombard, 2008). In order to establish relationships using culture and/or development these concepts have been dimensionalized. Authors have been able to establish relationships between cultural dimensions and development dimensions then concluded by saying either there is relationship or not between culture and development. The first challenge in conducting research involving culture is arriving at an understanding of what culture is, given the myriad of definitions, conceptualizations, and dimensions used to describe this concept.

Culture as it is defined, well understood and differentiates one group from the other, in more general form one country from the other. Culture then influences the behaviour and how people think in their everyday lives but so far culture of any group can only be measured in terms of a collection of cultural dimensions (Mazur, 2010). This has made it difficult to establish if there is any relationship between culture and any other social factors. In an event that one wants to find the influence of culture to society then one needs to find the influence of the individual dimensions of culture while at the same time talking about culture as a unit. The dimensionalization of culture entails we cannot talk about culture as a homogeneous unit but as a heterogeneous unit. Although there are measurements for cultural distance between nations to enable multinational companies to know the cultural distance between host-home countries, there is still no national culture index that can be used to measure any relationship with other social or economic factors (Zuva \& Worku, 2016). Researchers so far have relied on cultural dimensions to establish relationship between 
culture and other factors. Hofstede and Schwartz's cultural dimensions have usually been used for any relationship required (Beukelaer, 2013). It is therefore imperative to derive national culture index from the cultural dimensions available. Due to the absence of national cultural index there is no conclusive relationship that have been established between culture and other factors.

This research endeavoured to put the components/dimensions of culture together in order to visualize culture as a homogeneous unit and then attempted to find if there is any relationship between national culture and national development. The goal of the research is to derive national cultural index that can be used for effective investigation into relationship between culture and any other social or economic factors, in this case development of nations. This was accomplished by implementing the following primary objectives:

- To identify an appropriate formula to calculate national culture index using cultural dimensions

- To calculate/identify national development index of all the countries whose development dimensions are available

- To establish if there is any relationship between culture and development using the national culture index and the national development index.

The significance of finding the relationship between culture and development is that there is need to find out if culture impedes development or it facilitates development. This will enable people to consider changing their culture in order to facilitate development. If there is no relationship, then everyone can keep their culture without being forced to do so due to its negative effect on the societal development. This paper is arranged as follows: section 2-literature review, section 3-Methodology, section 4-Results and finally section 5-Conclusion.

\section{Literature Review}

According to (Minkov \& Hofstede, 2012) culture have an overwhelming tendency to form fairly distinct national clusters, therefore culture can be used to distinguish nations. They also acknowledge that despite the existence of in-country regional differences, the national culture is a meaningful concept and a legitimate unit of analysis. This means national culture can be used in establishing relationships with other social factors, it must be noted that this does not belittle the differences of culture within a nation. Many researchers have been trying to establish if there is any relationship between culture and development. The definition of the concepts of culture and development are so complex as seen from the definitions in (Morden, 2016; Orji \& Job, 2013; Minkov \& Hofstede, 2012; Albu, 2006; Aluko, 2003) to enable researchers to establish if there is any relationship between culture and development. This leads researchers to use dimensions of culture and dimensions of development to investigate if there is any relationship between culture and development (Beukelaer, 2013; Sempere, 2011; Maraña, 2010; Grosser \& Lombard, 2008; Mbakogu, 2004). Most of these researcher found out that some of the dimensions of culture have positive influence to development and others impedes development. The commonly used cultural dimensions are the ones proposed by Hofstede that are: power distance, uncertainty avoidance, individualism and masculinity as seen in (Yasemin Hancıoğlu, Ülkühan Bike Doğan, \& Yıldırım, 2014; McFarlin \& Coget, 2013; Gorodnichenko \& Roland, 2012; Parumasur, 2012). Some of the samples of conclusions of the relationship between national culture and other social factors are that Gross National Product (GNP) per capita was positively related to individualism and negatively related to power distance (Cox, Friedman, \& Tribunella, 2011). According to Tang and Koveos (2008), who proposed the use of a curvilinear relationship between GDP per capita and Hofstede's dimensions, found out that power distance first increase and then decrease with GDP per capita.

Hofstede national culture dimensions: The theory is based on the idea that value can be placed upon six cultural dimensions. These are power (equality versus inequality), collectivism (versus individualism), uncertainty avoidance (versus uncertainty tolerance), masculinity (versus femininity), temporal orientation, and indulgence (versus restraint). Hofstede gathered most of his data on world cultural values through surveys conducted by IBM, a US-based technology and consulting firm (Qamar et al., 2013). He then proposed a scoring system using a scale from 1 to 120 . Hofstede stresses that the cultural dimensions are only a framework to help assess a given culture and thus better guide decision making. There are other factors to take into consideration such as personality, family history, and personal wealth. The proposed dimensions cannot predict individual behaviours and do not take into account individual personalities (Hofstede, 2011). 
Power distance is explained as the level to which members of the society accept that power is distributed unequally. Collectivism indicates the degree to which individuals are integrated into groups. Uncertainityavoidance entails society's tolerance for uncertainty and ambiguity while masculinity depicts the level of how a society places on stereotypical masculine values such as assertiveness, ambition, power and materialism (Gouveia \& Ros, 2011). Temporal orientation describes a society's time horizon and indulgence measures a culture's ability to satisfy the immediate needs and personal desires of its members (Hofstede, 2011).

\section{Methodology}

This research will be using quantitative research method. The numerical representation of cultural dimensions will be used to derive the cultural index using Hofstede cultural dimensions. The geometric mean is used to calculate the cultural index as in equation 1.

$$
C I=\sqrt[4]{P D * U A * M S * I n}
$$

A linear regression approach is used for modeling the relationship between a scalar dependent variable (in this case it is the cultural index) and the explanatory variables (independent variables) (in this case Hofstede cultural dimensions) as in equation 2 .

$$
C I=a(P D)+b(U A)+c(M S)+d(I n)
$$

where PD is the power distance, UA uncertainty avoidance, MS masculinity and In is individualism. Development index is calculated using the numerical representation of life expectancy index (LEI), gross domestic income per capita (GDI per C) and education index (EI) (Bank, 2017).

The geometric mean is used to calculate the Development Index (DI) per year as given in equation 3.

$$
D I_{y}=\sqrt[3]{(L E I) *(E I) *(G D I \text { per } C)} \quad 3
$$

where LEI is life expectancy index, GDI per C is national Gross Domestic Income per Capita index and EI is education index.

The data used for the calculation of development indexes was taken from 2010 to 2014 UNDP data source and an average was obtained for the development index of nations as given in equation 4.

$$
D I=\frac{\sum_{y=1}^{n} D I_{y}}{n}
$$

The relationship between culture and development is tested using Pearson Correlation Coefficient (r) and Coefficient of determination (r-squared). The Cultural Index and Development Index data are used. Pearson Correlation is calculated using the formula 5.

$$
r=\frac{\sum_{i=1}^{n}\left(C I_{i}-\overline{C I}\right)\left(D I_{i}-\overline{D I}\right)}{\sqrt{\sum_{i=1}^{n}\left(C I_{i}-\overline{C I}\right)^{2} \sum_{i=1}^{n}\left(D I_{i}-\overline{D I}\right)^{2}}}
$$

where $\mathrm{CI}$ is cultural index and DI is the development index.

The important characteristics of $r$ are as follows:

- If $r=-1$, then there is a perfect negative linear relationship between $\mathrm{CI}$ and DI.

- If $r=1$, then there is a perfect positive linear relationship between CI and DI.

- If $r=0$, then there is no linear relationship between CI and DI.

Coefficient of determination is calculated using the formula 6.

$$
r^{2}=\frac{S S R}{S S T O}=1-\frac{S S E}{S S T O}
$$

where SSR is the "regression sum of squares" and quantifies how far the estimated sloped regression line is from the horizontal "no relationship line," the sample mean, SSE is the "error sum of squares" and quantifies how much the data points vary around the estimated regression line and SSTO is the "total sum of squares" and quantifies how much the data points vary around their mean. 


\begin{tabular}{l} 
Journal of Economics and Behavioral Studies (ISSN: 2220-6140) \\
Vol. 10, No. 2, pp. 145-154, April 2018 \\
\hline \hline
\end{tabular}

The important characteristics of r-squared are as follows:

- $\quad$ Since $r$-squared is a proportion, it is always a number between 0 and 1.

- If $r^{2}=1$, all of the data points fall perfectly on the regression line. The predictor CI accounts for all of the variation in DI!

- If $r^{2}=0$, the estimated regression line is perfectly horizontal. The predictor CI accounts for none of the variation in DI!

The coefficient of determination $r$-squared and the correlation coefficient $r$ quantify the strength of a linear relationship. The framework used in this study is shown in figure 1 . In the framework the $\mathrm{Cpd}, \mathrm{Cua}, \mathrm{Cm}, \mathrm{Ci}$ and $\mathrm{Cf}$ represent the correlation between the two entities. The values of these variables were found from the data used.

Figure 1: Framework used in the study

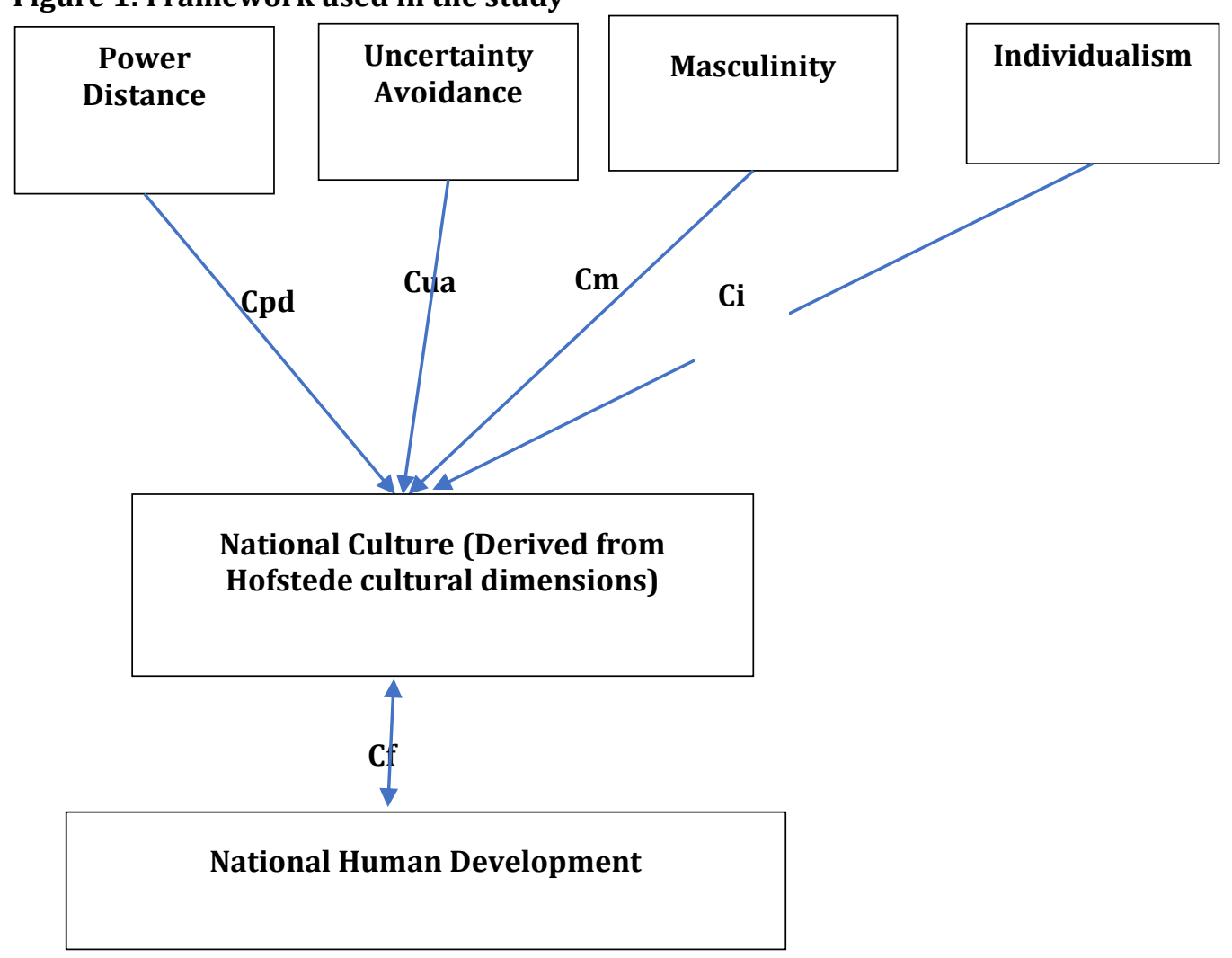

Data collection and analysis methods: This section describes how the data was collected and analyzed.

Data Collection Methods: Data collection can be divided into two categories - secondary and primary. Primary data is type of data which never existed before, hence it was not previously published. Primary data is collected for a specific purpose. Primary data collection methods can be divided into two categories: qualitative and quantitative. On the other hand, secondary data refers to a type of data that has been previously published in for example journals, magazines, newspapers, books, online portals and other sources. This research will be using secondary data. There are several reasons for using secondary data in this research. Secondary data that is available is entirely appropriate and wholly adequate to draw conclusions and answer the question or solve the problem. In this case primary data collection is not necessary. It is far cheaper to collect secondary data than to obtain primary data. The time involved in searching secondary sources is much less than that needed to complete primary data collection. Secondary sources of information can yield more accurate data than that obtained through primary research. This is not always true but where a government or international agency has undertaken a large-scale survey, or even a 
census, this is likely to yield far more accurate results than custom designed and executed surveys when these are based on relatively small sample sizes. These reasons have made us to use secondary data.

The secondary data used in this study is taken from Hofstede cultural dimensions' data that is freely available for academics on the Internet. Geert Hofstede conducted what many consider as the most comprehensive study of how values in the workplace are influenced by culture. He analysed a large database of employee values scores collected by IBM, between 1967 and 1973, covering more than 70 countries, from which he first used the 40 largest only and afterwards extended the analysis to 50 countries and 3 regions. In the editions of Geert Hofstede's work since 2001, scores are listed for 76 countries and regions, partly based on replications and extensions of the IBM study on different international populations. http://geerthofstede.com/researchand-vsm/.The other secondary data used for development is taken from United Nation Development Programme (UNDP) website http://hdr.undp.org/en/data. The permission to use the data was requested and was granted. The Data for Gross National Income per Capita is retrieved from The World Bank website http://data.worldbank.org/ that have an open license.

Analysis Methods: This research used quantitative data analysis and a quantitative data analysis software SPSS. Chart, table, histogram, diagram is used in the analysis of data where appropriate.

Sampling: This research used homogeneous purposive sampling a non-probability sampling method. The method was chosen because the research requires nations that have all the cultural dimension's data and also the human development national index data.

Ethical consideration: To address issues related to ethical consideration in a research there is need the methods of data collection that the research study is going to use. In studies that involve primary data collection ethical issues can be addressed by making sure that the following commitments are adhered to:

a) Respondents are going to participate in the survey voluntarily;

b) Questionnaire/Interview/Focus group questions are not going to contain offensive, discriminatory, or other unacceptable language;

c) Privacy and anonymity of sample group members are going to be maintained etc;

d) The works of other authors that are going to be used in any part of the proposed study are going to be acknowledged with the use of referencing system such as Harvard, APA, etc.

e) The author will attempt to maintain high levels of objectivity in discussions and analyses throughout the research.

In studies that do not involve primary data collection, on the other hand, ethical issues are going to be limited to the points d) and e) above.

In this research, the ethical issues are limited to the point d) and e) since the research is going to use secondary data.

Data source for our experiments for Hofstede dimensions of national cultures values will be retrieved from Hofstede website (Hofstede \& Hofstede, 2015). The license of use is as given below:

"Academic use: The VSM is freely available for academic research purposes under the following conditions of good practice:

- The researcher has qualified her- or himself by the careful study of at least one of the following books: Geert Hofstede (2001), "Culture's Consequences: Comparing Values, Behaviors, Institutions, and Organizations Across Nations", second edition, or Geert Hofstede, Gert Jan Hofstede and Michael Minkov (2010), "Cultures and Organizations: Software of the Mind", third edition.

- The VSM is used for the purpose for which it was designed, that is the comparison of culturally relevant values between matched respondent samples from two or more societies (countries, nations or regions).

- The VSM is not used for comparing organizations, occupations, other social categories or individuals.

- The VSM is not used for one-country replications without a match to compare with.

- The research findings are freely available to the academic community."

Data for human development national index was retrieved from UNDP website (Jahan, 2015) (Letter of consent was sent to the authors). 


\section{Results}

The regression analysis was done in order to get the estimated relationship between the dependent variable (Cultural Index) and the independent variables (Uncertainty avoidance, Masculinity, Individualism and Power distance). The size of the regression coefficients for each independent variable represents the mean change in the dependent variable for one unit of change in the independent variable while holding other independent variables in the model constant. The p-value of a coefficient is also important in regression analysis in that when it is less than the chosen significance level, such as 0.05 , the relationship between the independent and the dependentvariables is statistically significant otherwise insignificant.R-squared of the regression is another variable that needs to be considered; it is defined as the fraction of the variation in dependent variable that is accounted for (or predicted by) the independent variables.Table 1 shows the results from SPSS application and the equation below shows the relationship.

\section{Table 1: Regression analysis results}

\begin{tabular}{|c|c|c|c|}
\hline Output & ated & Note & es \\
\hline \multicolumn{4}{|c|}{ Variables Entered/Removed ${ }^{a}$} \\
\hline Model & Variables Entered & Variables Removed & Method \\
\hline 1 & $\begin{array}{l}\text { Uncertainity Avo, } \\
\text { Masculinity, } \\
\text { Individualism, } \\
\text { Power Distanœe }^{\circ}\end{array}$ & & Enter \\
\hline
\end{tabular}

a. Dependent Variable: GCDI

b. All requested variables entered.

\begin{tabular}{cc|c|c|c}
\multicolumn{4}{c}{} & \multicolumn{2}{c}{ Model Sum mary } & Std. Error of the \\
Model & $\mathrm{R}$ & $\mathrm{R}$ Square & Adjusted R Square & Estimate \\
\hline 1 & $.962^{\mathrm{a}}$ & .925 & .921 & 3.158 \\
\hline
\end{tabular}

a. Predictors: (Constant), Uncertainity Avo, Masculinity, Individualism, Power

Distance

\begin{tabular}{|c|c|c|c|c|c|c|}
\hline \multicolumn{7}{|c|}{ ANOVA $^{a}$} \\
\hline \multicolumn{2}{|c|}{ Model } & $\begin{array}{l}\text { Sum of } \\
\text { Squares }\end{array}$ & df & Mean Square & $\mathrm{F}$ & Sig. \\
\hline \multirow[t]{3}{*}{1} & Regression & 7668.702 & 4 & 1917.175 & 192.287 & $.000^{\circ}$ \\
\hline & Residual & 618.164 & 62 & 9.970 & & \\
\hline & Total & 8286.866 & 66 & & & \\
\hline
\end{tabular}

a. Dependent Variable: GCDI

b. Predictors: (Constant), Uncertainity Avo, Masculinity, Individualism Power Distance

\begin{tabular}{|c|c|c|c|c|c|c|}
\hline \multicolumn{7}{|c|}{ Coefficients $^{a}$} \\
\hline \multirow[b]{2}{*}{ Model } & & \multicolumn{2}{|c|}{ Unstandardized Coefficients } & \multirow{2}{*}{$\begin{array}{c}\text { Standardized } \\
\text { Coefficients } \\
\text { Beta }\end{array}$} & \multirow[b]{2}{*}{$\mathrm{t}$} & \multirow[b]{2}{*}{ Sig. } \\
\hline & & $\mathrm{B}$ & Std. Error & & & \\
\hline \multirow[t]{5}{*}{1} & (Constant) & -14.127 & 2.453 & & -5.758 & .000 \\
\hline & Power Distance & .277 & .024 & .530 & 11. 368 & .000 \\
\hline & Individualism & .343 & .021 & .746 & 16. 195 & .000 \\
\hline & Masculinity & .295 & .020 & .512 & 14.379 & .000 \\
\hline & Uncertainity Avo & .261 & .017 & .540 & 15.063 & .000 \\
\hline
\end{tabular}

a. Dependent Variable: GCDI

The results in table 1 show that the R-squared is approximately ninety-three percent (93\%), which is a very good fraction of the variation in our dependent variable that is accounted for (or predicted by) our independent variables. The R-squared is also very important to us since we would like to use the regression equation to make accurate predictions. The regression coefficients are all positive (Power Distance $=0.277$, $\mathrm{p}<0.01$, Individualism $=0.343, \mathrm{p}<0.01$, Masculinity $=0.296, \mathrm{p}<0.01$, Uncertainty Avoidance $=0.261, \mathrm{p}<0.01$ ) with a $\mathrm{p}$ value less than one percent indicating that the coefficients are statistically significant. 
The formula for the Cultural Index (CDI) is given in equation 7:

$$
C D I=0.277 P D+0.343 I D V+0.295 M A S+0.261 U A I-14.127
$$

The correlation between the national Cultural Index and Hofstede's cultural dimensions' index was done in order to find the degree to which they are associated. Correlation is a statistic that measures the linear relationship between two variables. The range of possible values for correlation coefficient ( $\mathrm{r}$ ) is from -1.0 to +1.0. Numbers less than zero represent a negative relationship between variables and numbers greater than zero represent a positive relationship. The value zero $(0)$ means there is no relationship that exists between the two variables. The analysis of our results on correlation coefficients used the interpretation in Figure 2.

\section{Figure 2: Correlation coefficient interpretation}

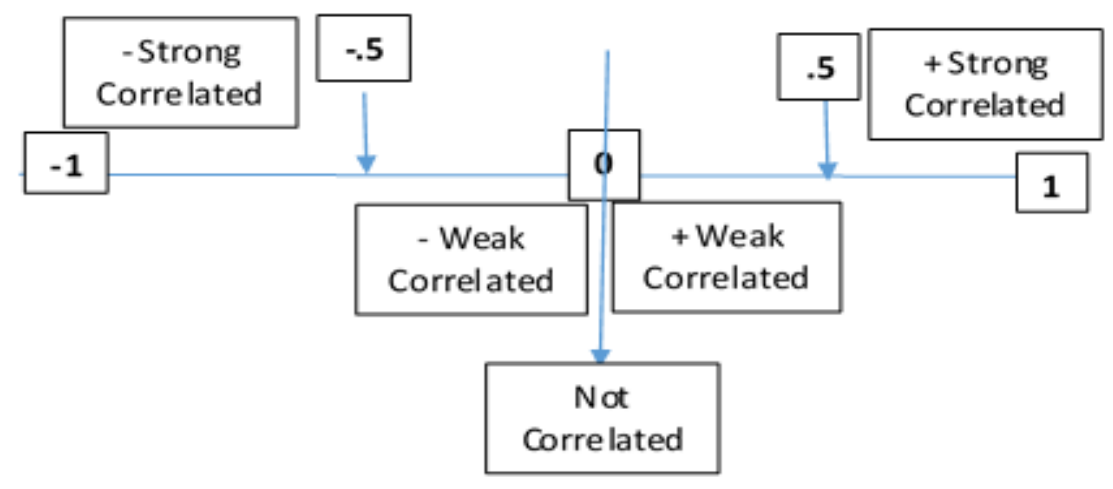

In our study the correlation coefficients were found through the use of SPSS application. The results are shown in Table 2.

Table 2: The strength of relationship between national Cultural Index and Hofstede Cultural Dimensions Index

\begin{tabular}{|c|c|c|c|c|c|c|}
\hline \multicolumn{7}{|c|}{ Correlations } \\
\hline & & $\mathrm{GCDI}$ & Power Distance & Individualism & Masculinity & Uncertainity Avo \\
\hline \multirow[t]{3}{*}{$\mathrm{GCDI}$} & $\begin{array}{c}\text { Pearson } \\
\text { Correlation }\end{array}$ & 1 & $.240^{\circ}$ & $.316^{-}$ & $.594^{-}$ & $.479^{-}$ \\
\hline & Sig. (2-tailed) & & .050 & .009 & .000 & .000 \\
\hline & $\mathrm{N}$ & 67 & 67 & 67 & 67 & 67 \\
\hline \multirow[t]{3}{*}{ Power Distance } & $\begin{array}{l}\text { Pearson } \\
\text { Correlation }\end{array}$ & $.240^{\circ}$ & 1 & $-.641^{-}$ & .127 & .229 \\
\hline & Sig. (2-tailed) & .050 & & .000 & .308 & .062 \\
\hline & $\mathrm{N}$ & 67 & 67 & 67 & 67 & 67 \\
\hline \multirow[t]{3}{*}{ Individualism } & $\begin{array}{l}\text { Pearson } \\
\text { Correlation }\end{array}$ & $.316^{-}$ & -.641 & 1 & .051 & -.216 \\
\hline & Sig. (2-tailed) & .009 & .000 & & .679 & .080 \\
\hline & $\mathrm{N}$ & 67 & 67 & 67 & 67 & 67 \\
\hline \multirow[t]{3}{*}{ Masculinity } & $\begin{array}{l}\text { Pearson } \\
\text { Correlation }\end{array}$ & .594 & .127 & .051 & 1 & -.042 \\
\hline & Sig. (2-tailed) & .000 & .308 & .679 & & .733 \\
\hline & $\mathrm{N}$ & 67 & 67 & 67 & 67 & 67 \\
\hline \multirow[t]{3}{*}{ Uncertainity Avo } & $\begin{array}{c}\text { Pearson } \\
\text { Correlation }\end{array}$ & $.479^{-}$ & .229 & -.216 & -.042 & 1 \\
\hline & Sig. (2-tailed) & .000 & .062 & .080 & .733 & \\
\hline & $\mathrm{N}$ & 67 & 67 & 67 & 67 & 67 \\
\hline
\end{tabular}

*. Correlation is significant at the 0.05 level (2-tailed).

**. Correlation is significant at the 0.01 level (2-tailed). 
The results show that the calculated culture index is positively correlated to all the Hofstede's cultural dimensions. It can be noted that culture index has a weak correlation with power distance $(r=0.240, p<0.05)$ and individualism $(\mathrm{r}=0.316, \mathrm{p}<0.01)$, has a relatively positive strong correlation with uncertainty avoidance $(\mathrm{r}=0.478, \mathrm{p}<0.01)$ and a positive strong correlation with masculinity $(\mathrm{r}=0.594, \mathrm{p}<0.01)$. All the $\mathrm{p}$ values are less than 0.05 indicating that the correlations are significant. In answering the research question of the study we then computed the correlation of the National Cultural Index and National Development Index. The results are shown in Table 3.

Table 3: The strength of relationship between National Cultural Index and Average National Development Index

\section{Correlations}

\begin{tabular}{llr|r}
\multicolumn{3}{c}{ Correlations } & \\
& \multicolumn{1}{c}{ Human index } & \multicolumn{1}{c}{ GCDI } \\
\hline Human index & Pearson Correlation & 1 & .083 \\
\cline { 2 - 4 } & Sig. (2-tailed) & & .502 \\
\cline { 2 - 4 } & $\mathrm{N}$ & 67 & 67 \\
\hline \multirow{3}{*}{ GCDI } & Pearson Correlation & .083 & 1 \\
\cline { 2 - 4 } & Sig. (2-tailed) & .502 & \\
\cline { 2 - 4 } & $\mathrm{N}$ & 67 & 67 \\
\hline
\end{tabular}

The results show that the correlation of National Culture Index and National Development Index is a very weak positive correlation $(\mathrm{r}=0.083, \mathrm{p}=0.502>0.05)$. Due to the fact that $\mathrm{p}$-value is greater than the significance level of 0.05 , there is inconclusive evidence about the significance of the association between the variables that is National Culture Index and National Development Index. The results obtained in Table 2 and Table 3 are illustrated in Figure 3.

The results show that Hofstede's cultural dimensions are positively correlated to the national culture index with the minimum degree of association of 0.24 with $\mathrm{p}$ less than five percent (5\%)indicating that the correlations are all significant. The correlation of national culture index and national development index is 0.083 which is approximately zero, showing lack of any meaningful or significant relationship between culture as a homogeneous entity and national development also as a homogeneous entity. Due to the value of $\mathrm{p}$ which is greater than the significance level of 0.05 , we conclude that there is inconclusive evidence about the significance of the association established between National Culture Index and National Development Index. 
Figure 3: Results of the strength of relationship between entities

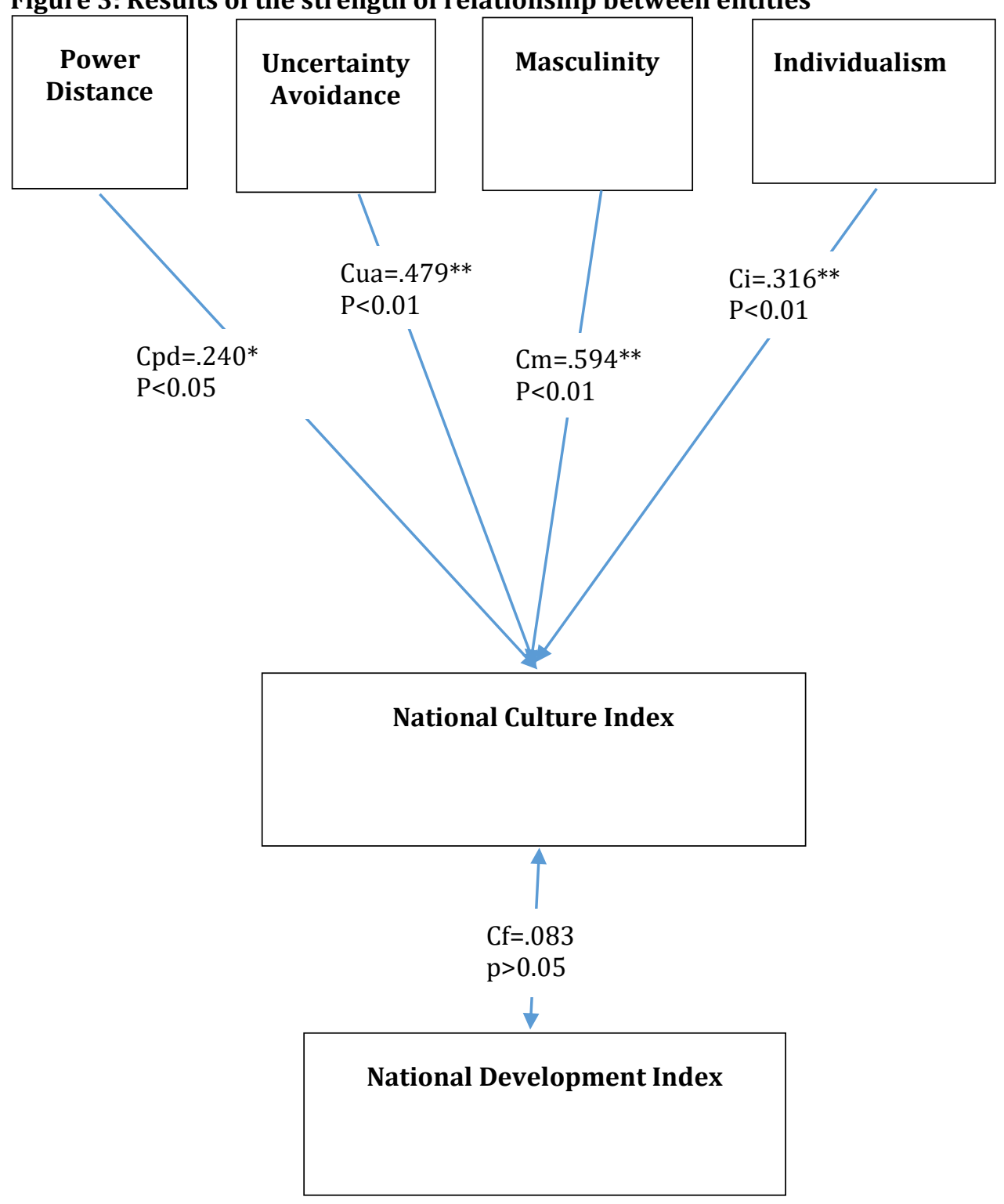

\section{Conclusion}

This study fulfilled the purpose and the study objective set out at the beginning. We managed to present a credible measure of culture as a unit. The national culture index may now be used in many other fields. In our case we wanted to establish whether there is any relationship between national culture and national development. We managed to use the national culture index to investigate the relationship. We can conclude that there is a very weak positive relationship between culture and development but this assertion is not conclusive. Further research needs to be undertaken to establish a conclusive conclusion. We recommend that the national culture index may be used to establish whether there is any relationship between culture and any of the dimensions of development. It can also be used to establish if there is any relationship between culture and any other social/economic factors.

\section{References}

Albu, M. (2006). Aspects regarding Hofstede's Cultural Dimensions Model. BULETINUL Universităţii Petrol Gaze din Ploiești, 98(4), 77 - 82. 
Aluko, M. A. O. (2003). The impact of culture on organizational performance in selected textile firms in Nigeria Nordic Journal of African Studies, 12(2), 164-179.

Beukelaer, C. D. (2013). Culture and development: a paradigm explored. Paper presented at the 5th European Conference on African Studies African dynamics in a multipolar world, Lisbon.

Cox, P. L., Friedman, B. A.\& Tribunella, T. (2011). Relationships amoung cultural dimensions, national gross domestic product and environmental sustainability. Applied Business and Enconomies, 12(6), 46-56.

Gorodnichenko, Y. \& Roland, G. (2012). Understanding the Individualism-Collectivism Cleavage and its Effects: Lessons from Cultural Psychology. Institutions and comparative economic development (pp. 1-30). Hampshire: Palgrave Macmillan.

Gouveia, V. V. \& Ros, M. (2011). Hofstede and Schwartz's models for classifying individualism at the cultural level: their relation to macro-social and macro-economic variables. Psicothema, 12, 25-33.

Grosser, M. \& Lombard, K. B. J. J. (2008). The relationship between culture and the development of critical thinking abilities of prospective teachers. Teaching and Teacher Education, 24(5), 1364-1375.

Hofstede, G. (Producer). (2011). Dimensionalizing cultures: The Hofstede model in context. Retrieved from Online Readings in Psychology and Culture. http://scholarworks.gvsu.edu/orpc/cont ents.html

Hofstede, G. \& Hofstede, G. J. (2015). Dimension Data Matrix. Retrieved 21 June, 2016, from http://www.geerthofstede.nl/dimension-data-matrix

Jahan, S. (2015). Human Development Report 2015 Work for Human Development Retrieved 21 June, 2016, from http://hdr.undp.org/en/composite/HDI

Maraña, M. (2010). Culture and Development Evolution and Prospects. Geneva: UNESCO Etxea.

Mazur, B. (2010). Culture diversity in organizational theory and practice. Journal of Intercultural Management, $2(2), 5-15$.

Mbakogu, I. A. (2004). Is There Really a Relationship Between Culture and Development? Anthropologist, 6(1), 37-43.

McFarlin, D. B. \& Coget, J. F. (2013). How does empowerment work in high and low power-distance cultures? Academy of Management Perspectives, 27(2), 1-3.

Minkov, M. \& Hofstede, G. (2012). Is national culture a meaningful concept? Cultural values delineate homogeneous national clusters of in-country regions. Cross-Cultural Research, 46(2), 133-159.

Morden, T. (2016). Principles of Strategic Management. London: Routledge.

Orji, K. E. \& Job, M. (2013). The role of education in national development: Nigerian experience. European Scientific Journal, 9(28), 312-320.

Parumasur, S. B. (2012). The effect of organisational context on organisational development (OD) interventions. SA Journal of Industrial Psychology, 38(1).

Qamar, A., Muneer, S., Jusoh, A. \& Idris, H. (2013). The Relationship between Organizational Conduct and National Culture. Journal of Economics and Behavioral Studies, 5(2), 82-88

Schwartz, S. H. (2008). Cultural value orientations: Nature and implications of national differences. Moscow: State University-Higher School of Economics Press.

Sempere, A. M. (2011). The Relations between Culture and Development in the Present Context1 Measures for the Economic Development of Underdevelopment Countries. New York.

Tang, L.\& Koveos, P. E. (2008). A framework to update Hofstede's cultural value indices: economic dynamics and institutional stability. Journal of International Business Studies, 39, 1045-1063.

Yasemin, H., Doğan, Ü. B. \& Yıldırım, Ș. S. (2014). Relationship between Uncertainty Avoidance Culture, Entrepreneurial Activity and Economic Development Procedia - Social and Behavioral Sciences, 150, 908-916.

Zuva, T. \& Worku, Z. (2016). Cultural differences of countries within a regional economic integration and their impact on stakeholders. International journal of Business and Management Studies, 8(2), 187-201. 